\title{
Pharmacy Phamilies as a Component of a Co-Curricular Program for Doctor of Pharmacy Students
}

Nancy A. Mason, PharmD; Jacqueline Dela Pena, PharmD Candidate; Bianca Campbell, PharmD Candidate; Burgunda V. Sweet, PharmD University of Michigan College of Pharmacy

\section{ABSTRACT}

Background: Pharmacy student professional growth depends heavily on co-curricular involvement, in addition to classroom learning. Co-curricular programming can be supported by an innovative structure using self-directed learning and a unique mentorship process. Innovation: A novel faculty and peer mentorship structure, called Pharmacy Phamilies, is integrated into a credited Lifelong Learning course that spans the 4 years of our PharmD program. This course is comprised of student-chosen activities to meet requirements in six domains, as well as reflections and other assignments. Recent changes include a new Pharmacy Phamily group reflection process and the use of co-curricular logs to document student activities.

Findings: Based on a student survey, the majority of respondents were satisfied with their level of engagement with their Pharmacy Phamily (72\%) and with their advisor (76\%). The majority also reported that the Pharmacy Phamily program is meeting its goals of establishing a sense of community at the college (76\%) and enhancing students' professional development (72\%). A total of $86 \%$ of students preferred the Pharmacy Phamily group reflection over the former six individual reflections and $93 \%$ of students agreed the cocurricular log was a useful tool to document involvement in professional activities.

Conclusion: Pharmacy Phamilies and peer-reviewed, group reflection can provide an inclusive structure of support and social connection for students at the college of pharmacy.

Keywords: co-curriculum, professionalism, student mentorship, reflection, pharmacy phamily

\section{BACKGROUND}

Successful pharmacists do not rely solely on clinical knowledge learned during pharmacy school; they also depend on experiences that lead to their professional growth. Professionalism may be broken down into many factors such as altruism, respect for others, dedication and commitment to excellence, responsibility, and lifelong learning. ${ }^{1,2}$ These qualities, along with the clinical knowledge obtained during pharmacy school, exemplify a successful pharmacist. However, these traits are not developed strictly within the didactic pharmacy curriculum; they also rely on co-curricular involvement. The 2016 ACPE Accreditation Standards for Pharmacy Programs reinforced the need for co-curricular programming and documentation. ${ }^{3}$ Since that time, pharmacy schools have been challenged to develop co-curricular programs, while grappling with a lack of direction regarding the incorporation of such programs into existing requirements. ${ }^{4} \mathrm{~A}$ recent survey of pharmacy programs ( $n=107$ responses, $74.8 \%$ response rate) found that most co-curricular approaches include student participation in self-selected patient care and non-patient care activities outside the classroom. ${ }^{5}$ Over $83 \%$ of programs reported using reflections or self-assessments as ways to document student completion of co-curricular requirements, with feedback provided mainly by advisors, course faculty, or staff. ${ }^{5}$ Activity tracking is accomplished mainly using electronic platforms by listing the activities completed, the hours completed, learning outcomes completed, or a combination of these items. ${ }^{5}$

Corresponding author: Nancy A. Mason, PharmD

University of Michigan College of Pharmacy

Email: nmason@umich.edu
The University of Michigan uses these basic elements, but they are incorporated into a structure with several unique aspects. In 2010, our college of pharmacy underwent a major curricular revision. As the new curricular plan was developed, faculty recognized the need for more structure and intentionality around student professional development, service, and other aspects of professional citizenship. As a result, a course called Lifelong Learning (LLL) was included as a requirement in each of the four years of the PharmD program. Lifelong Learning is a self-directed, longitudinal course that is conducted over the full four-year PharmD curriculum ( 0.5 credit per year). The cocurricular program is administered through the Student Services office with the Assistant Dean serving as LLL course director. Students choose approved co-curricular activities and complete assignments that provide for career exploration and personal and professional development (Table 1). Students are required to complete activities in six LLL domains, which all enrich didactic education and help students internalize the importance of self-directed learning. A wide array of activities are provided by student organizations and the college of pharmacy. In the academic year, 2018-19, this included 184 events. Events are submitted for LLL approval to the Assistant Dean of Student Services using an electronic event proposal system that was designed internally. Approved events are promoted through a bi-weekly Career Connections newsletter, where the LLL category designation is provided for each event. This allows students to choose upcoming events that fit their LLL requirements and are aligned with their areas of interest. Other assignments required in the LLL course are shown in Table 1. In 2010, in order to provide a more formal faculty advising and peer mentoring structure, the Pharmacy Phamily program was incorporated as a key component of the LLL course. In 2017, co-curricular logs were implemented as a means for students to document their activities. In 2017, to 
reduce the number of reflections and incorporate peer review through Pharmacy Phamilies, the reflection process was revised.

The purpose of this paper is to describe and evaluate the use of co-curricular logs and peer reviewed reflections. This paper will also share evaluative data on the use of Pharmacy Phamilies in the Lifelong Learning course.

\section{INNOVATION}

Pharmacy Phamilies provide mentorship and faculty advising for career and professional development and personal growth, as well as social connections among students and faculty. The value of personal connections at the collegiate level has been reinforced by data from the Gallup-Purdue Index 2015 Report, which assessed the perceptions of over 30,000 alumni concerning the value of their undergraduate college education. ${ }^{6}$ This study found that the most important factor was relationships with faculty and mentors, assessed by using the statements: 1) My professors cared about me as a person; 2) I had a mentor who encouraged me to pursue my goals and dreams; and 3) I had at least one professor who made me excited about learning. Strong agreement with any of these statements nearly doubled the odds that a graduate also agreed that their education was worth the cost. ${ }^{6}$ Even more importantly, the value of personal connection extends beyond a positive attitude toward the college experience. Strong social connections have been associated with better physical and mental health and a lower likelihood of substance or alcohol misuse in college students. ${ }^{7}$

Since our co-curricular program has been in place for many years, the innovations described here are focused on making the program more efficient, engaging and satisfying for the students while maintaining high quality experiences.

\section{DESCRIPTION OF INITIATIVES}

Pharmacy Phamilies are comprised of a faculty advisor and at least one student from each academic year (P1-P4). Students stay with the same faculty advisor and phamily members for their entire time at the college. All students are required to have at least one individual advisor meeting and one Pharmacy Phamily group meeting each semester, allowing for at least four live meetings between the student and their advisor per year. At individual advisor meetings, the student and professor review the SMART goals, curriculum vitae, and co-curricular activities and talk about the student's professional goals and accomplishments. These meetings are essential to the assessment of student progress in the affective domain and provide faculty advisors the opportunity to guide student growth in perceived areas of deficit. Phamily group meetings are less structured and more social, allowing for relationship, community building and peer mentoring. Through these gatherings, more experienced students can assist junior students by providing valuable insights into career exploration and job/residency/fellowship preparation.
Pharmacy Phamily advisors are volunteers from either the regular or adjunct faculty who are oriented to program expectations by the LLL course director. Advisors are acknowledged for their contribution to the program by a notation in their annual evaluation report and a \$250 annual bonus. Phamily gatherings may take the form of meetings, lunches, dinners, or special events (e.g., bowling, laser tag, escape rooms) based on advisor and group preferences. In order to reduce the pressure for advisors to fund expensive outings, the college hosts several Pharmacy Phamily group nights at the school each semester. Phamilies may reserve tables for a college-provided dinner. Groups often take advantage of this convenient opportunity to socialize over a meal.

For many years, reflections were required for each of the six LLL domain activities, in addition to the end-of-the-year overall reflection. Student feedback regarding the large number of reflection assignments in our program overall caused us to rethink the management of reflections in the LLL course. Beginning in the 2017-18 academic year, the six individual reflections in LLL were replaced with one Pharmacy Phamily Group Reflection. Using a Google document that is shared with students in the same phamily, each student writes a one-page reflection. Students are prompted to write about one meaningful experience or a set of related experiences that together resulted in significant learning or growth using the "what, so what, now what" format. ${ }^{8}$ All student phamily members are required to respond to at least two other students' reflections. This serves to reduce the number of reflections, which were considered busy work, and provides an opportunity for feedback and mentorship among students in each phamily. Completion of the each student's contribution to the group reflection document (both initial reflection and responses to others' reflections) is monitored by the LLL course director with assistance from Student Services office staff. A passing grade for the LLL course is withheld until this assignment and all other assignments are complete. All students also complete an individual year-end reflection that is reviewed by the faculty advisor and discussed with the student during their one-on-one meeting in the winter semester.

In the fall of 2017, co-curricular logs were incorporated into the LLL structure as a way of providing an easily accessible means for students to document their co-curricular activities. Earlier, documentation of LLL activities was accomplished by students writing a short reflection essay for each of 6 required experiences. Besides the overload of reflections mentioned earlier, a disadvantage of this approach was that only the minimum number of required activities were documented. This new co-curricular log based on Google sheets (Google LLC, Mountainview, CA) becomes a listing of each student's personal and professional development activities over their four-year academic career. Students are encouraged (but not required) to document all co-curricular activities on their logs. For each activity, students enter the date, event or activity name, location, LLL category, description, and number of hours spent. 
Students are trusted to record their participation truthfully; there is no verification of attendance. The logs, which are shared with the faculty advisor, align with LLL requirements and automatically tally LLL requirements by category by year and across years. The LLL course director monitors the logs each semester to ensure students are meeting the course requirements, as listed under LLL activities in Table 1.

\section{CRITICAL ANALYSIS}

To assess student perceptions of the key components of the cocurricular program, a prospective survey of students from the classes of 2019 (P4), 2020 (P3), and 2021 (P2) was conducted during fall 2018. Each cohort was asked to recall their experiences from the prior (2017-2018) academic year for all components of the co-curricular program. The survey included questions about their level of engagement with faculty advisors and Pharmacy Phamily student members, and whether the Pharmacy Phamily program is meeting its goals (Table 2). For students in the two cohorts that experienced both the individual and group reflection processes (classes of 2019 and 2020), there were survey items asking them to compare the perceived value of each process. Student perceptions of the cocurricular logs were also assessed. Deidentified data were analyzed using descriptive statistics. Item responses from the 5-point Likert scales were combined for analysis: Agree/Strongly Agree combined for level of agreement, and Moderately/Very/Extremely Well combined for achieving program goals. This study was deemed exempt from IRB oversight.

There were 104 of 250 students (42\%) who responded to the survey with response rates ranging from $25 \%$ for P4 students to $55 \%$ for P2 students. Table 2 shows findings related to Pharmacy Phamilies and program goals. Almost all of the students (98\%) reported meeting individually with their advisors at least twice, as required. Students who expressed dissatisfaction with their level of advisor or phamily engagement also tended to report that the program was not meeting its goals. The most common reported barriers were scheduling and time commitment. A common advantage of the Pharmacy Phamily program was the ability to network with peers and faculty.

When asked about reflection formats, $86 \%$ of students who had experienced both processes ( $\mathrm{P} 3$ and $\mathrm{P} 4$ students) indicated that they preferred the group reflection over the six individual reflections, citing the advantages of choosing an event that meant the most to reflect on (81\%) and better quality of the reflection (56\%). Only 37\% reported that receiving peer feedback from phamily members was an advantage. In retrospect, this may be explained by the lack of specific direction to students to go back and review the comments of others on their posted reflection. Over $82 \%$ stated that they put either the same or more effort into the group reflection compared to the individual reflections. A report by Vos et al. also described changes to their co-curriculum reflection process that reduced the number of written reflections and increased face-to-face meetings with faculty, in order to improve the value of the reflection process. ${ }^{9}$

When asked about the co-curricular logs, $93 \%$ of students agreed that it is a useful tool to document involvement in professional activities; level of agreement was similar across the P2, P3 and P4 cohorts. Students across the three cohorts reported that either most or all co-curricular activities were documented on the log (87\%), typically within a week of participating in an activity/event. The most commonly reported advantages of the co-curricular logs included: central location for documentation, visual display of co-curricular activities, and reference for updating curriculum vitae. Additional advantages included the log being used as a tool for reflection and talking points for future interviews. The most common barrier reported with the co-curricular log was difficulty documenting activities that could fit within multiple categories.

There were several limitations of this evaluation. Students were asked to recall their experiences with and attitudes towards elements of our program in the fall after several months of summer break. The study population was limited to students in our program, which is relatively small at about 250 students in the P2, P3 and P4 classes. Also, the response rate for the P4 class was low at $25 \%$. This is likely because they had moved into their APPE year and there were fewer opportunities to provide in-person reminders of the survey than for the other classes.

\section{NEXT STEPS}

While the co-curricular program has been in operation for 10 years, opportunities to refine processes continue to be identified. Improvements identified through this recent survey of students include adding a more formal process for student review of peer comments on their group reflections, clarifying the expectations of students and advisors regarding the topics to be discussed in advising meetings, and incorporating a process to identify phamilies that are not functioning well. Opportunities for improvement with the co-curricular logs include providing additional clarity on documenting activities that fall under multiple domains or require long-term involvement (e.g. chair of a student organization that meets regularly). We also plan to incorporate assessment of the cocurricular program components as a regular element of our quality assurance program. Since there is so little information published about best practices in pharmacy co-curricular programs, additional research in this area is warranted.

\section{CONCLUSIONS}

Our co-curricular program integrates a unique mentorship process that blends Pharmacy Phamilies and peer-reviewed reflection with our Lifelong Learning course, providing an inclusive structure of support and social connection for students at the college of pharmacy. The majority of students report being satisfied with the program and feel that it is meeting its goals. In addition, our co-curricular program was reviewed by ACPE during our fall 2019 accreditation review. The recent changes to Pharmacy Phamily group reflections 
replacing individual reflections and the addition of co-curricular logs were both viewed by students as positive enhancements to the program. The structure of this co-curricular program with the central elements of a Lifelong Learning Course and Pharmacy Phamilies serves as a successful template for other pharmacy programs that are seeking ways to develop and integrate co-curricular elements into their programs.

Funding/support: none

Conflicts of interest: none

\section{REFERENCES}

1. Lau MS, Wong FL, Russell T, et al. Tenets of Professionalism for Pharmacy Students. ACCP Student Commentary. Pharmacotherapy. 2009;29(6):757-759.

2. Eukel H, Frenzel J, Skoy E, Faure M. Longitudinal evaluation of student professionalism throughout the professional didactic curriculum of a pharmacy program. Curr Pharm Teach Learn. 2017;10(3):325-332. doi:10.1016/j.cptl.2017.11.011

3. Accreditation Council for Pharmacy Education. Guidance for the Accreditation Standards and Key Elements for the Professional Program in Pharmacy Leading to the Doctor of Pharmacy Degree ("Guidance for Standards 2016"). Published February 2015. Available at: https://www.acpeaccredit.org/pdf/GuidanceforStandards2016FINAL.pdf. Accessed October 14, 2020.

4. Patel UJ, Mediwala KN, Smith KM, et al. Carpe diem! Seizing the rise of co-curricular experiences. Am J Pharm Educ. 2017;81(8):Article 6702. doi:10.5688/ajpe6702.

5. Maerten-Rivera JL, Chen A, Augustine J, et al. Cocurriculum implementation and assessment in accredited doctor of pharmacy programs. Am J Pharm Educ. 2020; 84(3):7569. doi: 10.5688/ajpe7569.

6. Great jobs, great lives. The relationship between student debt, experiences and perceptions of college worth.

Gallup-Purdue Index 2015 Report. https://www.gallup.com/services/185924/galluppurdue-index-2015-report.aspx. Accessed Aug. 13, 2020.

7. Jorgenson DA, Farrell LC, Fudge JL, et al. College connectedness: the student perspective. J Scholar Teach Learn. 2018: 18(1):75-95. doi:10.14434/josotl.v18i1.22371.

8. Rolfe G, Freshwater D, Jasper M. Critical reflection in nursing and the helping professions: a user's guide. 2001. Basingstoke: Palgrave Macmillan.

9. Vos SS, Sabus A, Seyfer J, et al. Using continuing professional development to create meaningful cocurricular learning opportunities for all student pharmacists. Am J Pharm Educ. 2018: 82(4): Article 6270. doi: 10.5688/ajpe6270. 
Table 1. Required Activities for Lifelong Learning Course

SMART goals - one wellbeing goal and one professional goal

Curriculum vitae (CV)

LLL activities, one each from six domains*

- Advocacy

- Health Promotion

- Leadership

- Professional/career Development

- Service

- Shadow experience

Fall term group reflection with peer comments from Pharmacy Phamily

End-of-year reflection

End-of-year SMART goal progress report

Co-Curricular Log

Pharmacy Phamily or Advisor Meetings

- Fall Welcome Picnic (full phamily meeting)

- Book club discussion meeting (full phamily meeting)

- Fall term individual meeting with advisor (discuss SMART goals and CV)

- Winter term meeting with Pharmacy Phamily (full phamily meeting)

- End-of-Year reflection meeting (individual meeting with faculty advisor)

\footnotetext{
*LLL is intentionally designed to build expectations from the P1 to P3 years. P1 students are not required to complete LLL activities in the domains of Advocacy or Leadership, as they are novices to the profession and may not have opportunities to engage in these more advanced activities. Instead, they are required to complete 2 Shadow Experiences and 2 Professional/Career Development Activities, as well as one activity in each of the other domains. P2 and P3 students are required to complete an activity in each domain as stated above. P4 student activities are reduced to 2 LLL activities from any domain, as students are in their APPE year and are beginning their steps toward transition into their careers. They also mentor 2 Shadow Experiences for P1 students.
} 
Table 2. Student Perceptions of Pharmacy Phamilies

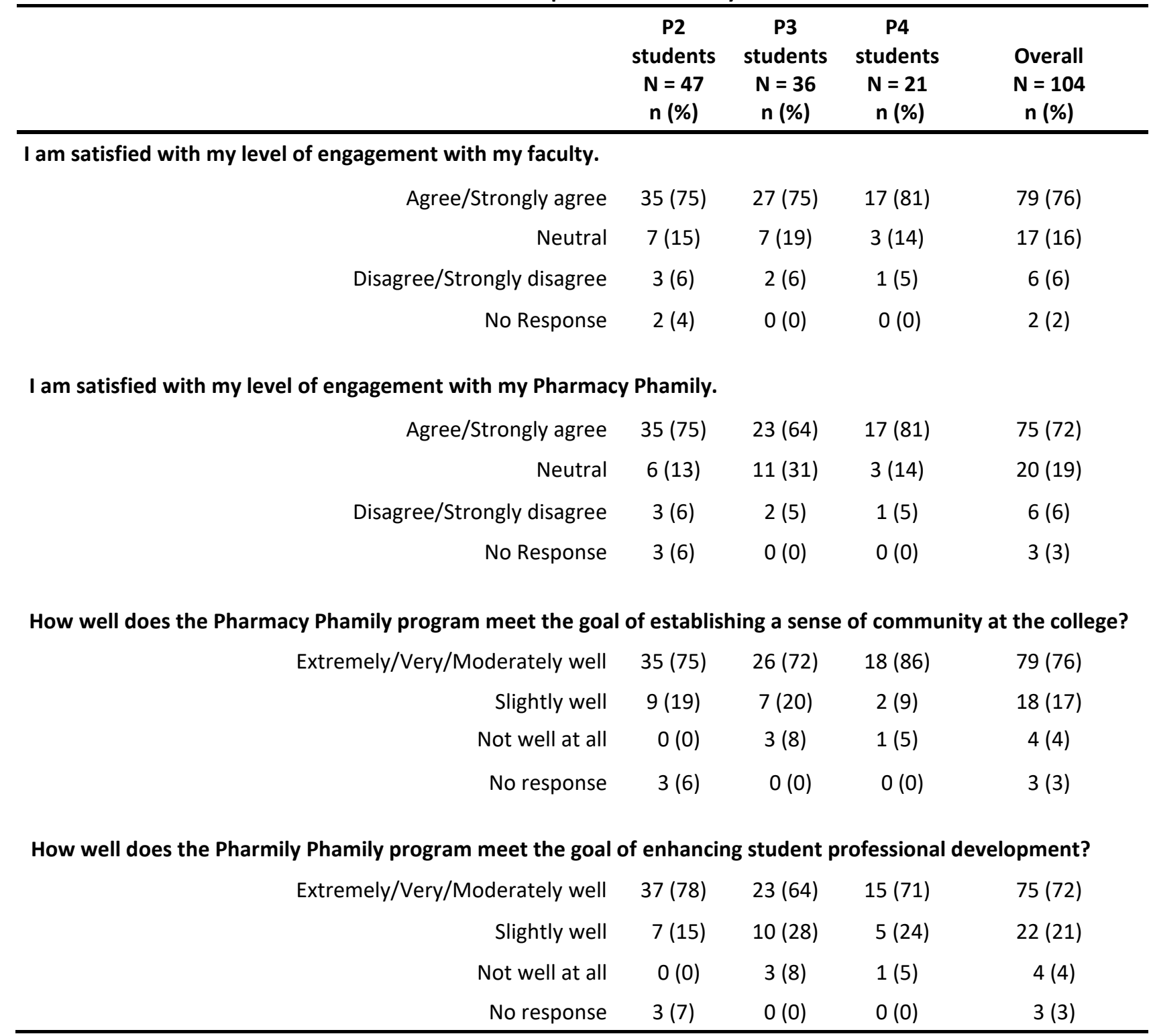

